favour such an extreme conclusion. What is missing from the synthesis is a close study of which policy actions are more important than others, given that the economics of greenhouse policy conflict with other social priorities.

Clearly there are empirical gaps in the climate policy literature, especially regarding financial cost. Thus, a first step in an international programme to slow global warming should probably include, for example, a diverse programme of reforestation to test Myers' data rigorously under real conditions. This research could be pursued in the near term without a fullblown climate agreement.

Beyond the wide range of scientific questions that remain unanswered, equally challenging is the need to develop effective policy measures which consider national styles of governance. Good greenhouse policy for one nation may not be appropriate for another, in light of disparate cultural, socioeconomic and environmental conditions; useful policy analyses of global warming must tackle these pragmatic concerns. For example, it

\section{Portrait of a dinosaur}

\section{Seth Shulman}

Seabrook Station: Citizen Politics and Nuclear Power. By Henry F. Bedford. University of Massachusetts Press: 1990. Pp.224. \$22.95.

IN the decade since the partial meltdown of the Three Mile Island Unit 2 reactor in Pennsylvania in 1979, the construction of new nuclear power plants in the United States has ground to a virtual halt. No new reactors have been ordered since the accident and all of the 47 units ordered since 1974 have ultimately been cancelled.

During this ignominious period for the US nuclear industry, the Seabrook nuclear plant in New Hampshire has stood as a powerful symbol of the faltering status of the industry - and of the wide-spread domestic opposition to nuclear power. Seabrook has now been licensed to operate, but angry critics and stalwart nuclear proponents alike rightfully see the process as a tragedy.

In 1967, when officials at a tiny New Hampshire public utility got the idea to build Seabrook, they planned two 1,100megawatt units at a projected cost of $\$ 425$ million each. Now, in 1990, the utility has only marginally survived the two-decade ordeal. It has gone bankrupt. It has managed to build only half of the plant envisioned initially. The plant's construction has divided communities across New England, the process has cost the utility - and ultimately ratepayers - an is not sufficient for the Greenpeace authors to note that methane (a strong greenhouse gas) could be reduced by feeding cows better food. Instead, policy recommendations must go further and provide workable approaches to the salient, practical questions such as: how do we convince a North American cattle rancher and an Indian herdsman to feed their cows better food?

The political will which has coalesced around global warming is admirable, but urgent calls for immediate policy action must recognize that (1) relevant science and policy fields remain underdeveloped, and (2) concern for the greenhouse should not eclipse other pressing problems of our time. As both studies argue persuasively, these factors should not paralyse policy response. But severe climate change is not the only risk; misdirected policy also poses a serious threat.

David Victor is at the Department of Political Science, Massachusetts Institute of Technology, Cambridge, Massachusetts 02139, USA.

astronomical $\$ 6,400$ million, an amount that will be nearly impossible to recoup no matter how high the cost of oil.

Bedford's book plumbs the depths of this remarkable story. This is not a referendum on the merits or hazards of nuclear power, but rather a lively, thoughtful and dispassionate look at a tangled and dysfunctional regulatory process. A book about bureaucratic politics may sound dull, but this one could never be so accused. Not with the high drama Bedford is able to chronicle; not with the cantankerous cast of characters involved every step of the way; and not with the nuclear hopes of so many tied to the success of the Seabrook project.

At face value, Seabrook's story is fascinating itself, but it is Bedford's analysis of the interminable proceedings that makes the book special. He offers a remarkably sympathetic portrait of each side of the struggle over Seabrook, but also shows how each repeatedly abused the system. Much of the debate in the later years of the licensing struggle at Seabrook revolved around the issue of evacuation in the case of an emergency. As Bedford shows, for many months the entire fate of this completed reactor rested to a large degree on whether, in the event of an accident, a school bus full of local residents would overstress a particular town bridge, thereby jeopardizing the planned evacuation process.

By most accounts, it is now clear that Seabrook's siting was a blunder. Poised on the edge of a crowded summer beach resort, the possibility of safely evacuating the summer population in the event of an accident is improbable at best. And yet the debate over siting was not allowed to take place in a meaningful way until the reactor was almost finished - hardly an ideal arrangement for either side. The residents, a great number of whom simply did not want Seabrook built in any form, stymied licensure by raising issues like the health of fish and the safety of bridges. These were ploys to stall - and hopefully stop - the plant altogether. Meanwhile, though, with so much money and vested interests resting on the plant, Bedford shows how the regulatory process was turned into a sham. The state and federal officials involved effectively rewrote almost every rule governing public safety to ensure the plant's operation. In essence, the process could be delayed, but the powerful players involved were not going to let the fate of an enormously expensive project be foiled by a bureaucratic technicality.

There is an important lesson here. As

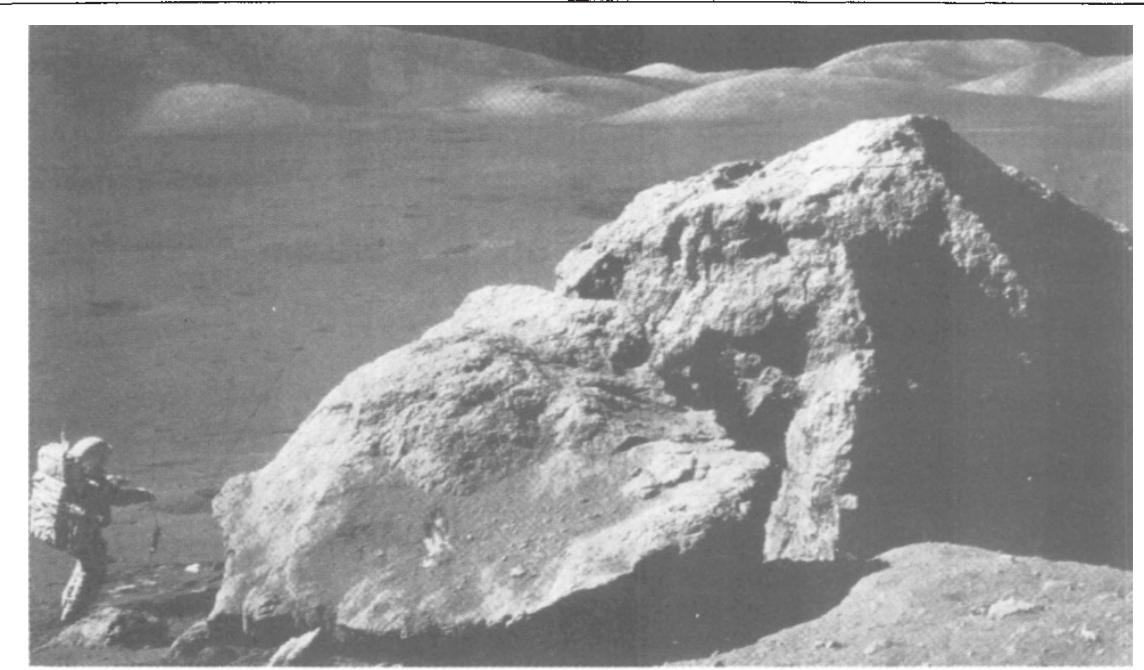

Man on the Moon - Harrison Schmitt, geologist and pilot of the Apollo 17 Lunar Module, examines an enormous broken rock on the Moon in 1972. The Cambridge Encyclopedia of Space edited by M. Rycroft is "the most complete and up-to-date account of the conquest of space" published in one volume. Publ ished by Cambridge University Press at $£ 40, \$ 65$ 
we learn in some detail, the US licensing process allowed groups to quibble for more than twenty years about the solidity of bridges, and the miniscule rise in ocean temperature caused by the plant; at no time in the process were people able to debate in a meaningful way the overarching issue of nuclear power, or the political and philosophical underpinnings of the participants that led them to such divergent views. Woefully, it seems, our society has yet to learn the process or vocabulary for such debates. Hence, technological questions of major importance to us all seem to get decided, if at all, in a shamefully ad hoc, de facto way.

If there is a flaw to Bedford's careful and clear case study of the Seabrook plant it is that he does not provide the reader with quite enough context fully to appreciate the circumstances. Most notable, of course, is the parallel story of Seabrook's sister reactor, the Shoreham plant in Long Island, New York. The unopened Shoreham plant has now been sold to New York state for one dollar, with the state assuming closing costs and vowing that the plant will never generate electricity. The divergent ends reached in these two cases make for a fascinating comparison: why did one constructed plant receive its licence whereas the other was effectively blocked by opponents? Similarly, Bedford could have offered more general background of the status of nuclear power in the United States. On economics issues, for example, he admirably explains the complexity of the financing as Seabrook's small public utility went ever more deeply into debt. But Bedford might have offered a bit of context here as well: all of the several lingering nuclear plants under construction during this period faced skyrocketing costs. Such a comparative perspective might have reminded us of the broader world in which Seabrook operated.

But this was not Bedford's aim. Rather he sought to do a close portrait of one dinosaur, and as such his work succeeds splendidly. In the end we learn much about how not to conduct public debate about technology. But we also learn how so many poor decisions could have been piled on top of each other to allow such an ill-advised project to proceed. The reasons are complex, but they are also caricatured beautifully by an administrator early on in Bedford's book advancing his so-called dinosaur theory to explain the Seabrook phenomenon. As Bedford writes, the administrator asks, "If you have a dinosaur in your backyard, you have to keep feeding it, because what can you do with a dead dinosaur?" We have only to watch the nearby Shoreham plant, I suppose, for answers.

Seth Shulman is at 28 Bates Road, Watertown, Massachusetts 02172, USA

\section{Indigestible science?}

\section{Ken Ducatel}

The New Technology. By Dimitris N. Chorafas. Sigma: 1990 (marketed by John Wiley and Sons Ltd). Pp. 410. $£ 14.95$.

THERE have been many recent books which have brought advances in science to the attention of a wider audience. Current media interest in issues such as the new physics, chaos theory, cosmology, genetics and artificial intelligence undoubtedly originates in popular science books written by specialists in these fields.

What we still lack is an accessible, but properly documented, overview of the implications of advances in science and technology for medium to long-term industrial strategy. With the widespread recognition of the salience of new technologies in competitive performance such a book has a guaranteed market amongst industrialists and policy makers. Yet it does not exist. It seems that the main reason why this book has still to be written is that it would be incredibly hard to do well. Not only would it have to summarize the technologies quickly, simply and accurately, it is also notoriously difficult to forecast technological progress accurately.

Good authorial style would be crucial. It takes a certain skill to make science digestible to a general audience whilst not being howled down by the experts in the field. It would also be necessary for instance to observe scientific rules about the presentation of information, such as adequate attribution and accuracy in the use of data, as well as extensive use of visual devices and conceptual models to convey the substance of the sometimes elegant, sometimes complex subject matter.

We may also ask, how confident an author can be in identifying the precise areas of technical advance which will be economically important in the next ten to twenty years. It is hard enough to forecast with precision how fast single new technologies are gaining acceptance in the commercial world. When it comes to describing the interaction between economic forces and an array of new technologies, accurate forecasts are out of the question. The only solution to the forecasting problem is a powerful explanatory model of the process by which new systems of technology are introduced into society. In the past there have been periods of great economic change and crisis as an existing system of technology burns out and is shaken out of the economy and the new technological system is installed. We have been undergoing just such a period of shift in the "technoeconomic paradigm" since the early 1970 s. The rate of adoption of new technologies and therefore their significance to industrialists and policy makers will depend upon their relation to the point in the cycle of these paradigms which we have reached. By using a powerful concept such as the techno-economic paradigm, order can be imposed on the book's analysis of the economic and social consequences of competing science and technology developments.

A full plan for the book on future technologies for concerned managers cannot be worked out here, but its fundamental features are given above. It would have to be written in an accessible but reflective style, so that justice is done to scientific knowledge. It would also need a strong conceptual core, to give the reader an orientation to the overall streams and currents of technological change. Unfortunately, although apparently recognizing that the niche exists, Dimitris Chorafas has produced a book which fails to meet these criteria. I will restrict my discussion to three basic problems: style, attribution and structure.

First, the writing style of the author is idiosyncratic to say the least. In what is apparently an attempt to write in a downto-earth style, he uses short choppy sentences, sometimes dispensing altogether with the verb in the sentence. There are instances where the author's use of English is so strange as to make the text incoherent and in some cases laughable. A howler such as "winds of change can be seen" (page 15) is merely an example. The general effect is of a rather rushed translation by someone who is not a native English speaker. Second, the book lacks any systematic reference system; despite the author's habit of copious name dropping, few references are listed. The lack of attribution in popular nonfiction is justified on the grounds that full referencing obstructs the flow of argument. In this book it is symptomatic of a general neglect of appropriate standards in the reporting of scientific knowledge. Readers not familiar with an area who want to follow up points which are being made in the text will find this impossible, as the book lacks even a guide to further reading. Graphs and tables suffer a similar fate with, in most cases, no attributed source and in some cases no scale on the axes.

Third, the book lacks a central conceptual approach, beyond the theme that 'science is discovery is progress'. As a result the discussion of the different technological developments is without focus. The book styles itself as a survival guide for the $1990 \mathrm{~s}$, which would imply that it should be used as a resource to gain access to some of the leading-edge technological developments. In the absence both of a systematizing conceptual model of how 